\title{
Steven Woloshin, Lisa M. Schwartz, H. Gilbert Welch: Know Your Chances: Understanding Heath Statistics
}

\author{
142 pages. Berkeley: University of California Press; 2008. \$16.95. \\ ISBN-13: 978-0-5202-5222-6
}

\author{
Brian P. Lucas
}

Published online: 27 April 2010

(C) Springer 2010

This is a math-friendly primer of numeracy that trains patients to "know the outcome; get the numbers!" Potential consumers of the primer can, rather unusually, review experimental evidence about its efficacy before they buy it, because the authors compared an earlier version of the primer to a generic, control booklet in two randomized trials [1]. The control booklet was similar in length and reading level, but unlike the primer, it did not include training on how to interpret numbers. Given the current state of numeracy, however, a potential consumer may not be able to meaningfully translate the trials' numbers into a value-driven decision about whether or not to buy Know Your Chances. Therefore, I will apply the self-study curriculum from Know Your Chances to interpret the results of these trials and, in doing so, make full use of this unusual circumstance.

What Is the Risk? Readers learn to first identify the outcome. Ideally, a primer of numeracy would study the quality of health care decisions made by its readers. Yet for practical reasons, performance on a medical data interpretation test was the outcome studied in the trials. Primer readers learn to recognize a surrogate outcome like this one as a shortcoming, just as the authors dutifully did in their original paper.

B. P. Lucas $(\bowtie)$

Department of Medicine, Cook County Hospital,

1901 West Polk Street, Room 520,

Chicago, IL 60612, USA

e-mail: brian_lucas@rush.edu
How Big Is the Risk Reduction? Next, readers learn to find the "starting" risks. They then learn to compare these risks to "modified" risks, using absolute differences. In both trials, there was a reduction in the risk of failing by 18 percentage points in the groups given the primer. (Taking the primer's advice on reframing outcomes, I present the inverse of passing the test, the outcome presented in the original paper.) Readers learn to favor absolute risk reductions, although smaller and superficially less impressive than relative risk reductions. The number conversion table at the back of the book can help readers put this risk reduction in perspective: about " 1 in 6 " fewer people would fail the test if given the primer.

What Are the Downsides of This Risk Reduction? Readers learn to postpone final decisions about whether or not reductions in risk are worthwhile until they have considered the downsides. The primer costs less than 20 dollars, and its 142 pages of readable type with plenty of illustrations will not take more than a few hours to read.

Does This Risk Information Apply to Me? Readers learn to trust numbers when participants in research studies are similar to them. Participants from both trials were mostly middle-aged, white, and in good health. And, whereas those in one trial were mostly women from a high socioeconomic status, those in the other trial were mostly men from a low socioeconomic status. Readers learn to gauge if such characteristics match up to their own.

What Science and People Are Behind the numbers? More than one supportive randomized trial presented in a 
peer-review journal tempers the healthy skepticism that primer readers may invoke because the authors of the trials were also the authors of the primer.

In the end, readers learn to make final conclusions about potential actions by weighing benefits and downsides. Based on the self-study questions applied above, Know your chances is a worthwhile purchase. In fact, numerate clinicians would likely come to this conclusion from the published trials alone, without ever applying the primer's curriculum. Nevertheless, even the most numerate clinicians among us would benefit greatly from Know your chances, because it expertly models communicating risk information, a critical skill that most of us rarely do well, if at all.

\section{References}

1. Woloshin S, Schwartz LM, Gilbert Welch H (2007) The effectiveness of a primer to help people understand risk. Ann Intern Med $146: 256-265$ 